Roodbeen, R.T.J., Schelleman-Offermans, K., Lemmens, P.H.H.M. Can vendors' age limit control measures increase compliance with the alcohol age limit? An evaluation of measures implemented by three Dutch liquor store chains. International Journal of Drug Policy: 2018, 61(11), 7-14

Postprint version :

Journal website

: $\quad$ https://www.sciencedirect.com/science/article/abs/pii/S095539591830 2342?via\%3Dihub

Pubmed link

DOI

: /10.1016/j.drugpo.2018.09.006

This is a Nivel certified Post Print, more info at nivel.nl

\title{
Can vendors' age limit control measures increase compliance with the alcohol age limit? An evaluation of measures implemented by three Dutch liquor store chains
}

\author{
Ruud T.J. Roodbeen $^{\text {a, b }}$, Karen Schelleman-Offermans ${ }^{\text {c, d }}$, Paul H.H.M. \\ Lemmens $^{d}$
}

\begin{abstract}
Background

Dutch liquor store (off license) chains have voluntarily developed and implemented age limit control measures to increase compliance with the Licensing and Catering Act (LCA), aimed at prohibiting vendors from selling alcohol to minors ( $<18$ years old). This study investigates differences between three liquor store chains in their style of self-regulation and how that affects compliance with the LCA in four domains (capturing processes in age verification, instructing staff, monitoring performance/providing feedback and imposing consequences).

Methods

A mixed-method design was used. In depth-interviews $(n=3)$ were conducted with chains' head office managers, gaining insight into control measures. Survey $(n=372)$ research was conducted to measure liquor store owners' perceptions of implementation. Mystery shop ( $n=387$ ) research was conducted to measure compliance of store owners with the LCA. Survey and mystery shopping data was linked $(n=179)$ for the indicated perceived risk of inspection.

Results

The interviews indicated that control measures differ across chains in comprehensiveness and degree of implementation, survey results showed corresponding differences across the chains. Linked results showed that liquor store owners who perceive a very high risk of inspection, showed higher ID requesting rates (chain 2 and 3: 93\% and 99\%) and compliance rates (chain 2 and 3: 77\% and 86\%), respectively. This effect may be amplified by a set of measures (e.g., by implementing age verification systems, increasing training, monitoring performances and/or imposing consequences) and could result in higher ID
\end{abstract}


Roodbeen, R.T.J., Schelleman-Offermans, K., Lemmens, P.H.H.M. Can vendors' age limit control measures increase compliance with the alcohol age limit? An evaluation of measures implemented by three Dutch liquor store chains. International Journal of Drug Policy: 2018, 61(11), 7-14

request rates (chain 1: $54 \%$ versus chain 2 and 3: both 95\%) and compliance rates (chain 1: $35 \%$ versus chain 2 and 3 : both $80 \%$ ).

Conclusion

A comprehensive and systematic implementation of specific combinations of control measures in all four domains resulted in high compliance rates up to $80 \%$. Nevertheless, the expectation is that this effect can only be attained when complemented by external government enforcement efforts.

\section{Introduction}

Several studies have concluded that the extent to which alcohol is available for young people influences their use and related health impacts, and that access to alcohol can be reduced by setting age limits (Babor, Caetano, \& Casswell, 2010; Everitt \& Jones, 2002; Huckle \& Parker, 2014; Kypri et al., 2006; Paschall, Grube, \& Kypri, 2009; Wagenaar \& Toomey, 2002; Wagenaar, 1993). The effectiveness of age limits depends, however, on the degree to which they are complied with (Babor et al., 2010; Reynolds, Holder, \& Gruenewald, 1997). The Dutch liquor store (off license) sector showed a compliance rate of $61.8 \%$ in 2016 (Roodbeen \& Schelleman-Offermans, 2016). Although above the national average compliance rate of $35.8 \%$ for all alcohol sellers (on and off premise), still over $38.2 \%$ of the 17-year-old mystery shoppers could buy alcohol at liquor stores (Roodbeen \& SchellemanOffermans, 2016). This high non-compliance is especially a concern since only liquor stores are allowed to sell spirits (drinks concentrated with $>15 \%$ pure alcohol) in the off-premise sector in the Netherlands (Rijksoverheid, 2014).

\section{Dutch legislation and the liquor store sector in context}

According to the Dutch Licensing and Catering Act (DLCA), vendors are prohibited to sell alcohol to minors, and are obliged to determine the age of the potential buyer (if the buyer is not unmistakably over 18 years of age) by requesting a formal identification document (ID) (Rijksoverheid, 2014). In January 2013 , the enforcement for the sale of alcohol was decentralized to local municipalities, and in January 2014, the legal age limit for the sale and purchases of all alcoholic beverages was increased from 16 to 18 years (Rijksoverheid, 2014). These changes were accompanied by a substantial increase of attention in politics and the media regarding underage alcohol availability and triggered liquor store chains to voluntarily formulate self-regulated age limit control measures. Regarding the enforcement of age limits, the DLCA does not specify any statutory or mandatory requirements regarding the enforcement of age limits. This means that the responsibility for implementation and enforcement of age limit control measures are left with vendors. The setting of statutory drinking age limits cannot be considered self-regulation in the strict sense of the word, i.e. voluntary regulation by societal parties and stakeholders (such as the industry). The Dutch government, however, has decentralized enforcement of this law as a municipal task (each council is obliged to create an enforcement plan), and has put responsibility for proper execution of the ban with the sellers of alcoholic drinks (and to a small degree to juvenile individuals). Self-regulation here means that the central government has only set objectives and does not prescribe specific procedures for observing these limits for sellers, leaving proper execution to the discretion of parties in the field.

From a broad perspective, literature on self-regulation focusing on tobacco, alcohol and the ultraprocessed food and drinks industries show that there is no evidence for the effectiveness or safety of self-regulation (Anderson, Chisholm, \& Fuhr, 2009; Moodie et al., 2013; Sharma, Teret, \& Brownell, 2010). Furthermore, focusing on the alcohol market, the development or promotion of a (new/existing) voluntary code or other form of self-regulation is used to reduce political pressure (Mosher, 2012; Savell, Fooks, \& Gilmore, 2015), regarding happy hours (Van Hoof, Noordenburg, \& Jong, 2008), advertisement (Hope, 2006; Jackson, Hastings, Wheeler, Eadie, \& Mackintosh, 2000; Smith, Cukier, \& Jernigan, 2014), marketing campaigns (Casswell \& Thamarangsi, 2009; Committee, 
Roodbeen, R.T.J., Schelleman-Offermans, K., Lemmens, P.H.H.M. Can vendors' age limit control measures increase compliance with the alcohol age limit? An evaluation of measures implemented by three Dutch liquor store chains. International Journal of Drug Policy: 2018, 61(11), 7-14

2010; Mosher, 2012; Munro, Wever, \& de, 2009; Noel, Babor, \& Robaina, 2017) and alcohol health warning labels (Mathews, Thorn, \& Giorgi, 2013). In addition, the alcohol market is known to argue that their own self-regulation is working well or is working better than formal regulation (Committee, 2010; Fogarty \& Chapman, 2012; Munro \& Wever, 2009; Nelson, 2010), arguing that existing regulation is satisfactory (Committee, 2010; Hope, 2006), of more extensive than necessary (Committee, 2010; Jernigan, 2012). Because of this, a critical assessment and evaluation of these selfregulated measures is important, since strict control on age limits may conflict with economic interests.

Liquor store chains and age limit control measures; the present study Off-premise alcohol in the Netherlands is sold by liquor stores, cafeterias (snack bars and/or small diners), supermarkets, convenience/night shops and home delivery outlets. Only liquor stores are allowed to sell spirits (>15\% proof) off-premise (Rijksoverheid, 2014). In 2016, 2442 liquor store permits were issued allowing the sale of spirits ("VDN (VDN (Vereniging Drankenhandel Nederland). (n.d.), 2018). Approximately $30 \%$ of all liquor stores are chain-organized. Dutch liquor store chains consist of affiliated liquor stores (liquor stores owned by the chain) and/or franchise liquor stores (liquor stores owned by the liquor store owner). One of the differences between the two are the legal consequences chains can impose on store managers and employees. For instance, within a franchise collaboration, the chains can only impose on store owners, not employees. In an affiliated collaboration, both parties (the store manager and employees) work for the chain and agree to possible consequences in their contract. From 2012 onward, all stores affiliated with the trade organization VDN, together with the Dutch supermarket affiliation (CBL), agreed on a voluntary code of conduct to request a valid and original ID for all individuals appearing younger than 25 years (Roodbeen, Schelleman-Offermans, \& Lemmens, 2016). Furthermore, all affiliates committed themselves to a systematic, four-step approach on age verification in the purchasing process, which aims to increase compliance: 1) age estimation, 2) request for a valid ID for those estimated up to 25 years of age, 3) review the ID, and 4) decide whether to sell the product, or not. In addition to these collective measures, liquor store chains have individually implemented age limit control measures, aiming to self-regulate age verification to increase compliance.

Four types of policy domains indicated by the Dutch Food and Product Safety Authority (NVWA) are, when addressed systematically, important for achieving high compliance rates (Hermans, Peeters, \& Beerepoot, 2009). The first one is capturing processes in age verification, and involves the systematic, four-step approach on age verification in the purchasing process. Previous research has shown that requesting ID increases compliance (Roodbeen, Lie, \& Schelleman-Offermans, 2013; Van Hoof, Roodbeen, Krokké, Gosselt, \& Schelleman-Offermans, 2015). Furthermore, the supportive usage of age verification systems (AVSs), calculating and confirming whether the customer reached the legal purchase age, significantly increases the odds for compliance (Roodbeen et al., 2016; Van Hoof, Gosselt, \& de Jong, 2010). Logically, this measure should be implemented as a start. Secondly, instructing staff could possibly increase compliance. For instance, responsible beverage service training, designed to reduce disorder and alcohol related harm, have shown potential (Brennan, Moore, Byrne, \& Murphy, 2011; Scherer, Fell, Thomas, \& Voas, 2015; Shapiro \& Kazemi, 2017). Presumably, the training and/or instruction of off-premise alcohol vendors can have a similar positive effect on compliance. The instruction of staff can only be properly executed when processes in age verification are captured and implemented in the organization, therefore, instructions should be sequential to the first measure. Thirdly, monitoring performance/giving feedback could be important to achieve high levels of compliance because of its ability to change and improve unwanted outcomes (Alvero, Bucklin, \& Austin, 2001; Grube, DeJong, DeJong, Lipperman-Kreda, \& Krevor, 2018; Roscoe, Fisher, Glover, \& Volkert, 2006; Rothengatter, 1991; Van Hoof, Gosselt, Baas, \& De Jong, 2012). Performance feedback is successfully used in a variety of organizational settings (e.g., alcohol establishments, university hockey teams, electric utility industries, textile factories). A similar positive 
Roodbeen, R.T.J., Schelleman-Offermans, K., Lemmens, P.H.H.M. Can vendors' age limit control measures increase compliance with the alcohol age limit? An evaluation of measures implemented by three Dutch liquor store chains. International Journal of Drug Policy: 2018, 61(11), 7-14

effect on compliance in the liquor store chain organization structure could be expected (Alvero et al., 2001; Grube et al., 2018; Roscoe et al., 2006; Rothengatter, 1991; Van Hoof et al., 2012). Monitoring performance/giving feedback is only feasible if employees are instructed properly and age verification processes are in order. Lastly, regulations and laws seem to be ineffective when they are not enforced (Reynolds et al., 1997). Therefore, in addition to monitoring and feedback, imposing consequences based on non-compliance with the age limit is needed to achieve high compliance rates.

In this study, differences are investigated between liquor store chains in their style of self-regulation and how that affects compliance with legal requirements concerning alcohol sales to minors. Control measures are analyzed in four regulatory domains, followed by the perceived implementation at shop floor level and an evaluation on compliance with the alcohol age limit.

\section{Methods}

A mixed-method design was used. In-depth interviews were conducted with managers of the liquor store chains for gathering insights into control measures. Using surveys, liquor store owners were asked about the implementation of their chain's control measures. Mystery shopping was used to measure compliance. Survey and mystery shopping data was linked for the indicated perceived risk of inspection.

\section{In-depth interviews}

\section{Population and sampling}

In 2015, managers of the 3 liquor store chains (all males) were invited via email to participate to an indepth interview, all accepted the invitation. The interviews were done before the survey data collection started, all managers were interviewed separately and face to face. During two interviews, a total of 3 public relation colleagues also participated ( 2 females and 1 male).

\section{Measures}

Semi-structured in-depth interviews (approximately $1 \mathrm{~h}$ ) were conducted in which the managers were asked to describe their age limit control measures within four domains: 1) capturing processes in age verification, 2) instructing staff, 3) monitoring performance/giving feedback, 4) imposing consequences.

\section{Analyses}

The interviews were transcribed and independently analyzed by two researchers (QSR, 2014). The transcripts and preliminary results were all sent to the managers for feedback (member checks). All inconsistencies in coding were resolved through discussions between two researchers.

\section{Surveys}

\section{Participants}

In the fall of 2015, cross-sectional data were collected over a six-week period on store-level implementation of control measures in the four domains. Liquor store owners or shop managers of three liquor store chains were included (the same chains also used in the interviews and mystery shopping study). A total of 721 store owners were invited to complete the survey (104 out of 825 stores (12.6\%) could not receive an invitation caused by technical defects). Within a two-week period, a total of $298(41.3 \%)$ online surveys were retrieved. After two weeks, a reminder was sent to the remaining liquor store owners, resulting in an additional response of $74(10.3 \%)$, summing up to a total response of $51.6 \%(n=372)$. Table 1 describes characteristics of participants. To avoid identification, the number of stores per chain will not be mentioned. 
Roodbeen, R.T.J., Schelleman-Offermans, K., Lemmens, P.H.H.M. Can vendors' age limit control measures increase compliance with the alcohol age limit? An evaluation of measures implemented by three Dutch liquor store chains. International Journal of Drug Policy: 2018, 61(11), 7-14

\section{[table 1]}

\section{Procedure}

All 721 store owners received a link in their inbox or a link was placed on their personal portal-page (intranet). The introduction page explained the organizations involved, the goal of the study, ethical considerations (anonymity of the liquor store and the liquor store owner), the approximate length of the survey (between 10 and $15 \mathrm{~min}$ ), and contact details of researchers for questions or remarks. If surveys could not be completed at once, the participant could close it and resume at any other time.

\section{Measures}

1) Capturing processes in age verification. Due to social desirability bias, store owners were not asked about their own performance. All the necessary steps (compliance, ID requests, and the use of an AVS) were measured with the use of mystery shopping research. 2) Instructions for staff. Store owners were asked which training/instruction type they used: individual oral training, group oral training, giving written information, E-learning module or practical training using age verification systems. 3) Monitoring performance/giving feedback. Perceived risk of inspection by the liquor store chain was measured on a Likert-type scale ( $1=$ very low $-5=$ very high) as indicator for the degree of monitoring. 4a) Imposing consequences on staff by liquor store owner/manager. Liquor store owners were asked in 7 multiple response questions to indicate which specific types of consequences were applied to their staff whenever non-compliance with the age limit was found: personally addressing staff member, a written warning, obligatory additional training, a note in the personnel file, mandatory interview with the head office manager, suspension or dismissal). 4b) Imposing consequences on liquor store owners by chains' head office. Liquor store owners were asked to indicate which types of consequences applied to themselves or the store whenever non-compliance with the age limit was observed in their store: personally addressed by chains' head office, written warning from head office, obligatory additional training, obligatory additional training of their staff members, and mandatory interview with the head office manager.

\section{Analyses}

Comparisons between the three chains were made on the above described control measures: 1) applying different types of training/instructions for their staff, 2) indicating the perceived risk of inspection by their head office (monitoring performance), and 3 ) indicating various consequences for themselves and their staff (imposing consequences). Chi-square tests were conducted analyzing possible differences between the chains.

\section{Mystery shopping}

\section{Population and sampling}

In the fall of 2015, cross-sectional data were collected over a four-week period in the liquor stores of the three chains. Sample sizes were calculated assuring a 95\% confidence level $(\alpha=.05)$ for each individual chain separately (total $n=825$ ). Sampling was stratified by liquor chain, region (the North, East, South or West) and population density, assuring a regionally representative sample for each individual chain. Based on these strata, a total of 387 liquor stores were selected randomly, and visited by 17 -year old boy or girl-mystery shoppers (balanced design for gender). At each store, one underaged mystery shopper performed one purchase attempt of $a>15 \%$ alcohol product $(n=194$; spirits), or a $<15 \%$ alcohol product ( $n=193$; e.g., beer or wine). The selected liquor stores were not aware of the specific period and time in which the purchase attempts would be carried out. 
Roodbeen, R.T.J., Schelleman-Offermans, K., Lemmens, P.H.H.M. Can vendors' age limit control measures increase compliance with the alcohol age limit? An evaluation of measures implemented by three Dutch liquor store chains. International Journal of Drug Policy: 2018, 61(11), 7-14

\section{Ethics in mystery shopping}

Data collection took place in accordance with validated protocols for mystery shopping research, including ethical and legal aspects regarding this type of research, as described and conducted in previous mystery shopping studies (Gosselt, Van Hoof, de Jong, \& Prinsen, 2007; Roodbeen et al., 2016; Van Hoof et al., 2015). The method used in this study is not deemed to be medical research, subjects are not manipulated or adversely affected in any way, and is for this reason exempted under the Dutch WMO-law which is the legal charter of the Helsinki Declaration (CCMO, 1999). All mystery shoppers were accompanied by experienced adult mentors trained and assigned by the research institute, who oversaw the entire procedure from a distance in a discrete way. The procedure secured the anonymity, privacy and legal integrity of the liquor store's employees, mentors and mystery shoppers. Study results are not reducible to individuals and will never be used for penalizing vendors. If purchase attempts interrupt enforcement efforts, the enforcement-officer will be informed by the mentor. Lastly, according to the DLCA, buying and the possession of alcohol is not illegal for adolescents in liquor stores, as long as the beverage container is not taken out of the store (Rijksoverheid, 2014). By handing the alcohol to an adult research supervisor, mystery shoppers avoid breaching the DLCA.

\section{Procedure}

The mystery shopper enters the liquor store and takes a can of alcohol from the shelves (wine/beer or spirits). Interaction with the vendor consists of showing a personal and valid ID if this is requested and lying about one's age ("I am 18 years old"). All mystery shoppers are trained to interact in this way and to recognize the presence and possible use of age verification systems (AVSs). When a purchase is allowed by the vendor, the mystery shopper pays for the product, and discreetly hands over the beverage container to the mentor during exit. After each purchase attempt, observations are recorded and the alcohol securely stored and sealed by the mentor. The alcohol was not consumed and all alcohol products were destroyed by the research institute.

\section{Measures}

The mystery shoppers assessed compliance, ID requests, and the use of an AVS by the cashier. Covariates were estimated age $(<20,20-40$ or $>40)$ of the cashier, and the gender of the cashier and mystery shopper.

Analyses

Results are presented for the complete dataset (showing all data) and the linked dataset (showing data from liquor stores who are tested using mystery shopping and have filled out the survey). Comparisons using Chi-square analysis are made between the three chains as to 1 ) requesting ID rates, 2) the total compliance rate and 3 ) the total compliance rate and requesting ID rates for several contextual variables (gender of vendors and mystery shoppers and the perceived age of vendors). In addition, differences between the complete and linked datasets on ID requesting and compliance rates are analyzed using Chi-square calculations.

\section{Linked survey- and mystery shopping results}

Data from liquor stores who have filled out the survey and are tested using mystery shopping are linked for the indicated perceived risk of inspection. Linking other domains (different types of training and consequences) with mystery shopping results was not feasible due to a limited cell-count and interpretability of categories within these domains. Chi-square test were conducted analyzing possible differences between the chains regarding the perceived risk of inspection (survey results) and the ID requesting and compliance rates for the 'very high' perceived risk of inspection category. 
Roodbeen, R.T.J., Schelleman-Offermans, K., Lemmens, P.H.H.M. Can vendors' age limit control measures increase compliance with the alcohol age limit? An evaluation of measures implemented by three Dutch liquor store chains. International Journal of Drug Policy: 2018, 61(11), 7-14

\section{Results}

Interview results; analysis of age limit control measures

Key differences between the chains on domains are presented in Table 2, regarding capturing processes in age verification, instructing staff, monitoring performance/giving feedback and imposing consequences.

\section{[table 2]}

\section{Capturing processes in age verification}

\section{Key differences}

During age verification, employees of chain 2 are obligated to do a more thorough or detailed inspection of ID's (they have to physically obtain the ID of the adolescent buyer and are obligated to perform a photo check). Also, chain 2 and 3 have fully implemented age verification systems (AVS provides sellers with a physical notification of the current date minus 18 years). The AVS used by these chains resembles the digital pop-up window AVS used in Dutch supermarkets (Roodbeen et al., 2016). Corresponding measures. All three liquor store chains indicated they are committed to the rules in the DLCA (Rijksoverheid, 2014), the code of conduct, and the four-step systematic approach of age verification, and all have captured age limit control measures in a plan or manual.

\section{Instructing staff}

\section{Key differences}

Chain 2 and 3 instruct their staff in a way that is more diverse and more intensive, compared with chain 1. For instance, new employees of chain 2 must pass an alcohol e-learning exam, if they succeed, they receive a certificate and are allowed to work in the store. New employees of chain 3 receive a rulebook, containing all the mandatory steps during age verification. Also, approximately five of six times a year, a magazine is published by chain 3 , with a discussion of the age limit subject from various perspectives. Furthermore, on a weekly basis, reminders of age verification rules and other age limit related information is published on the intranet portal of chain 2, and on a yearly basis, employees of chain 3 receive a personal letter containing the mandatory steps during age verification. In both cases (for both chains), a reading conformation by the employee is required. Corresponding measures. All three chains indicated that the first age limit instructions are provided by the store manager or owner during the job application; the rules in the code of conduct are discussed here. In addition, all new employees on store level must read, understand and sign (providing a reading confirmation) the steps mandatory during age verification (their stated age limit control measures) as part of their employment conditions/contract. All chains remind their employees of these mandatory steps and general rules regarding age verification at least once a year on their intranet-systems, in staff meetings or during general meetings with all the liquor store owners, discussing research findings (sometimes based on internal audits, enforcement efforts and other developments on the subject).

\section{Monitoring performance/giving feedback}

\section{Key differences}

Chain 2 and 3 monitor the performance of every liquor store using mystery shopping audits, chain 1 does not. Four times a year, chain 2 uses minor mystery shoppers ( $<18$ years), measuring compliance at every liquor store. In addition, they use adolescent shoppers once a year, measuring ID requests. Chain 3 uses minor and adolescent shoppers, each once a year, monitoring every liquor store. In 
Roodbeen, R.T.J., Schelleman-Offermans, K., Lemmens, P.H.H.M. Can vendors' age limit control measures increase compliance with the alcohol age limit? An evaluation of measures implemented by three Dutch liquor store chains. International Journal of Drug Policy: 2018, 61(11), 7-14

addition, chain 3 also uses minor mystery shoppers to monitor age verification during the home delivery of alcohol. In most cases, both chains use external firms for executing the audits, and feedback is delivered directly after the audit (permission is unequivocally granted by all employees of both chains). Additionally, the region/rayon managers of chain 2 (managers overviewing a certain number of liquor stores in a specific region) are specifically instructed to check the dates on the AVSs (they should be set on the current date), and check security cameras for the execution of age verification in previous days. Corresponding measures. The chains stated unanimously that the visits their region/rayon managers bring to the liquor stores are important in monitoring the performance of age verification. The region/rayon managers of all the chains pay these visits on a (approximately) weekly basis, visiting all of their assigned liquor stores.

\section{Imposing consequences}

The chains can legally impose consequences on store managers and employees of an affiliated liquor store (both parties work for the chain and agree to possible consequences in their contract), in franchise liquor stores, the chains can only impose consequences on the store owners, not the employees.

\section{Key differences}

The affiliate liquor stores of chain 1 have included the possibility of a salary reduction measure in the employment contracts if processes in age verification are neglected. The consequences imposed on by chain 2 and 3 are based on results obtained from the mystery shopping audits. In chain 2 and 3 , employees who neglected processes in age verification (after the first negative audit) receive a personal and formal letter from management. Employees of chain 3 also receive an official warning, which is included in their personnel file. If negative audits occur in a chain 2 store, all employees of that store receive a notification from the incident (improving team-spirit). Furthermore, employees of chain 2 have to pass the e-learning exam again and update their certificate, the employees of chain 3 are required to follow a mandatory training with the store manager at the head office of the chain. After a second negative audit, consequences for employees of chain 3 are a stern conversation with the region/rayon manager and a work suspension if necessary. After a third negative audit, dismissal could be a consequence for employees of chain 2 and 3. Employees can be dismissed after three errors when monitored by a mystery shopper. Store managers in chain 2 will be dismissed whenever they personally make an error. The franchisers of chain 1 and 3 (the store owners) are free in composing his or her own team of employees and possible consequences to impose on employees. In the franchise agreement is included that not complying to the law in general could lead to consequences for the liquor store owner, the specific content of consequences is unknown. Corresponding measures. The consequences that chains could impose on store managers and owners are captured in their general age limit control measures and in employment contracts.

\section{Survey results; the perceived implementation of age limit control measures}

\section{Instructing staff}

The number of liquor store owners/manager who apply individual oral trainings for their staff members did not differ between the chains (between $90 \%$ and $97 \%$ ). The application of all other types of training did significantly differ $(p<.05)$ between the chains, with chain 1 applying these training types to a lower degree (Table 3). 
Roodbeen, R.T.J., Schelleman-Offermans, K., Lemmens, P.H.H.M. Can vendors' age limit control measures increase compliance with the alcohol age limit? An evaluation of measures implemented by three Dutch liquor store chains. International Journal of Drug Policy: 2018, 61(11), 7-14

\section{[table 3]}

\section{Monitoring performance/giving feedback}

A majority of liquor store owners from chain 2 and 3 perceived a very high risk of inspection ( $84 \%$ and $87 \%$, respectively) by their head office compared to store owners from chain 1 (19\%; Table 3$)$.

\section{Imposing consequences}

Comparing the control measures between chains, it becomes clear that liquor store owners from chain 1 experience significantly fewer $(p<.000)$ consequences in case of non-compliance (all types) from their head office, compared to chain 2 and 3. Similarly, chain 1 store managers/owners are significantly less likely $(p<.000)$ to impose consequences on their own staff, with one exception; personally addressing staff.

\section{Mystery shopping results; analyzing compliance with the alcohol age limit}

Table 4 shows the descriptive results for purchase attempts of alcohol products per liquor store chain for the complete and linked datasets. In total, in 255 of the 387 attempts, vendors refused the sale of alcohol to the mystery shopper (66\% full compliance). In 317 out of the 387 attempts (82\%) vendors asked for the ID of the mystery shopper. Not all ID requests resulted in refusal of sale, resulting in $80 \%$ compliance after ID requests. Furthermore, after ID requests, AVSs were used 77 times (24\%). This resulted in compliance after use of $91 \%$. When comparing the chains, all compliance rates of chain 1 were lower compared to chain 2 and 3 in the complete and linked dataset $(p<.01)$. No significant differences were found between the complete and linked datasets regarding total ID requesting rates and total compliance rates. Lastly, regarding contextual variables, vendors estimated between 20 and 40 years of age comply significantly more often compared to vendors estimated younger than 20 years old or vendors estimated above 40 years of age (77\% compliance versus $50 \%$ and $59 \%$, respectively; $X 2=15.7, d f=2, p=.000$ ).

\section{[table 4]}

Linking survey and mystery shopping results; analyzing the perceived risk of inspection on compliance rates

The results from the linked dataset (Table 5) show that a majority of the liquor store owners of chain 2 and 3 perceive a very high risk of inspection ( $83 \%$ and $86 \%$, respectively) compared with store owners from chain 1 (23\%). The corresponding ID requesting rates ( $93 \%$ and $99 \%$, respectively) of store owners of chain 2 and 3 who perceive a very high risk of inspection are significantly higher than the ID requesting rates of store owners of chain 1 (71\%). Likewise, the corresponding compliance rates of store owners of chain 2 and 3 who perceive a very high risk of inspection are significantly higher $(77 \%$ and $86 \%$, respectively), compared with store owners of chain $1(43 \%)$. It appears that liquor store owners (in general) who perceive a very high risk of inspection, show higher ID requesting and compliance rates.

\section{[table 5]}

\section{Discussion}

The aim of the present study was to investigate the differences between liquor store chains in their style of self-regulation and how that affects compliance with legal requirements concerning alcohol sales to minors. The general conclusion is that if chains implement a specific combination of age limit control measures comprehensively, higher compliance rates with the alcohol age limit can be achieved. 
Roodbeen, R.T.J., Schelleman-Offermans, K., Lemmens, P.H.H.M. Can vendors' age limit control measures increase compliance with the alcohol age limit? An evaluation of measures implemented by three Dutch liquor store chains. International Journal of Drug Policy: 2018, 61(11), 7-14

Looking at specific measures, chain 2 and 3 have fully implemented age verification systems (AVSs), chain 1 has not. The vendors in chain 2 and 3 showed higher ID requesting rates (as high as $95 \%$ versus $54 \%$ for chain 1 ) and a relatively higher use of AVSs (up to $27 \%$ versus $18 \%$ for chain 1 ). The combined effects of these measures resulted in higher compliance rates for chain 2 and 3 after using AVSs (100\% for chain 2 and 93\% for chain 3). Other studies investigating similar AVSs in Dutch supermarkets (the digital pop-up window AVS) show less optimistic results when analyzing this specific AVS (Roodbeen et al., 2016). Liquor store chains could possibly benefit from an application of a more advanced AVS, which calculates and confirms whether the customer has reached the legal purchase age (e.g., keyingon-date-of-birth or ID swiper/checker AVSs), since these more advanced systems are proven effective in a supermarket context (Roodbeen et al., 2016).

Another control measure that might contribute to a higher compliance rate in chains 2 and 3 (up to $80 \%$ compliance versus $35 \%$ for chain 1 ), is the systematic monitoring of vendors' behaviour, leading to a significant high perceived risk of inspection for vendors of chain 2 and 3 . Our linked data on this domain cautiously demonstrates that, in general, a very high perceived risk of inspection improves IDrequests and compliance rates and this effect may be amplified by a set of measures (increased training, monitoring and strict consequences in case of non-compliance) imposed by liquor store chains on their store owners. However, despite clear differences between the chains in their perceived risk of inspection and mystery shopping results, it was not possible to estimate the direct effect of specific control measures on compliance, due to a limited cell-count of linked data (data from liquor stores who have filled out the survey and are tested using mystery shopping). If the cell-count is too low, this can lead to invalid results in analyses. In future studies, a larger sample is needed of sellers who fill out the survey and are tested by mystery shoppers (linked data). This creates the ability to perform multivariate analyses on the linked dataset with sufficient cell-count and controlling for relevant covariates (other measures) or combinations of measures that are performed. Additionally, in future studies, data collection of survey data should not be limited to store managers or store owners, but should be performed in several levels of the organizations (e.g., front-end staff and region/rayon managers). Another limitation arises due to the cross-sectional nature of the data, not ruling out reversed causation (a better compliance inspires a more elaborate control measure implementation). Furthermore, the low survey response rate of $52 \%$ and the likelihood of respondent bias (e.g., given the presence of public relation employees during the in-depth interviews) are limitations of this study that should be considered when interpreting the results.

Despite these limitations, this study shows that certain age limit control measures are linked to higher compliance rates. These results can offer chain managers and store owners guidelines when trying to improve compliant behaviour at the shop level. Additionally, chain organizations could use these results as a blueprint for introducing and implementing age limit control measures in their organization. Further research is needed for a more thorough investigation of differences in the implementation and enforcement of control measures between franchise or affiliate chainorganizations, and how control measures are evaluated within different layers in the chain organization. Of interest are, for example, the communication of control measures from the head office to the region/rayon managers to the alcohol vendor in the liquor store. In future research, stores not organized in chains or on-premise locations should not be ignored.

Despite measuring compliance rates up to $80 \%$ in this study, there is still much room for improvement. Even though it seems that age limit control measures increase compliance, it is quite likely that high compliance rates are only possible when the perceived risk of inspection is not only stressed from within the organization, but also from outside of the organization by external government enforcement efforts. Further research should additionally focus on the way government enforcement efforts influence the effectiveness of age limit control measures. 
Roodbeen, R.T.J., Schelleman-Offermans, K., Lemmens, P.H.H.M. Can vendors' age limit control measures increase compliance with the alcohol age limit? An evaluation of measures implemented by three Dutch liquor store chains. International Journal of Drug Policy: 2018, 61(11), 7-14

\section{Implications and contribution}

This study investigates differences between liquor store chains in their style of self-regulation, and how that affects compliance with legal requirements concerning alcohol sales to minors, using indepth-interviews, surveys and mystery shopping research in a mixed design. If measures are implemented comprehensively in specific combinations, higher compliance rates are achievable.

\section{Conflict of interest statement}

There are no conflicts of interest for all named authors.

\section{Funding}

Data collection of the mystery shopping research was supported by the Dutch trade organization for liquor store chains and liquor trade (VDN). Data collection and analyses of the interviews and surveys were funded by Nuchter, Centre for Research on Age Restrictions. The views expressed by the authors do not necessarily represent those of the funding bodies.

\section{Acknowledgements}

The authors thank VDN for facilitating mystery shopping data collection in 2015. Furthermore, the authors thank participants, research assistants and mystery shoppers for their valuable contribution to the study.

\section{References}

1. Alvero, A. M., Bucklin, B. R., \& Austin, J. (2001). An objective review of the effectiveness and essential characteristics of performance feedback in organizational settings (19851998). Journal of Organizational Behavior Management, 21(1), 3-29. https://doi.org/10.1300/J075v21n01_02.

2. Anderson, P., Chisholm, D., \& Fuhr, D. C. (2009). Effectiveness and cost-effectiveness of policies and programmes to reduce the harm caused by alcohol. The Lancet, 373(9682), 2234-2246. https://doi.org/10.1016/S0140-6736(09)60744-3.

3. Babor, T. F., Caetano, R., \& Casswell, S. (2010). Alcohol: No ordinary commodity: Research and public policy, Vol. 2nd R. Oxford: Oxford University Press.

4. Brennan, I., Moore, S. C., Byrne, E., \& Murphy, S. (2011). Interventions for disorder and severe intoxication in and around licensed premises, 1989-2009. Addiction (Abingdon, England), 106(4), 706-713. https://doi.org/10.1111/j.1360-0443.2010.03297.x.

5. Casswell, S., \& Thamarangsi, T. (2009). Reducing harm from alcohol: Call to action. Lancet (London, England), 373(9682), 2247-2257. https://doi.org/10.1016/S01406736(09)60745-5.

6. CCMO (1999). Central committee on research involving human subjects. http://www.ccmo.nl/.

7. Committee, H. (2010). House of commons health committee, Vol. I. Everitt, R., \& Jones, P. (2002). Changing the minimum legal drinking age-its effect on a central city emergency department. New Zealand Medicine Journal, 115, 9-11.

8. Fogarty, A. S., \& Chapman, S. (2012). Advocates interest groups and Australian news coverage of alcohol advertising restrictions: Content and framing analysis. BMC Public Health, 12(1), 727. https://doi.org/10.1186/1471-2458-12-727.

9. Gosselt, J. F., Van Hoof, J. J., de Jong, M. D. T., \& Prinsen, S. (2007). Mystery shopping and alcohol sales: Do supermarkets and liquor stores sell alcohol to underage customers? Journal of Adolescent Health, 41(3), 302-308. https://doi.org/10.1016/j.jadohealth.2007.04.007. 
Roodbeen, R.T.J., Schelleman-Offermans, K., Lemmens, P.H.H.M. Can vendors' age limit control measures increase compliance with the alcohol age limit? An evaluation of measures implemented by three Dutch liquor store chains. International Journal of Drug Policy: 2018, 61(11), 7-14

10. Grube, J. W., DeJong, W., DeJong, M., Lipperman-Kreda, S., \& Krevor, B. S. (2018). Effects of a responsible retailing mystery shop intervention on age verification by servers and clerks in alcohol outlets: A cluster randomised cross-over trial. Drug and Alcohol Review, 1-8. https://doi.org/10.1111/dar.12839 November 2017.

11. Hermans, C. V. S., Peeters, T. P. L., \& Beerepoot, R. (2009). Inventarisatie werkwijze leeftijdsgrenzencontrole bij supermarkten [an inventory of age verification procedures in supermarkets]. Utrecht: Berenschot.

12. Hope, A. (2006). The influence of the alcohol industry on alcohol policy in Ireland. NORDIC STUDIES ON ALCOHOL AND DRUGS, 23(6), 467-481.

13. Huckle, T., \& Parker, K. (2014). Long-term impact on alcohol-involved crashes of lowering the minimum purchase age in New Zealand. American Journal of Public Health, 104(6), 1087-1091. https://doi.org/10.2105/AJPH.2013.301734.

14. Jackson, M. C., Hastings, G., Wheeler, C., Eadie, D., \& Mackintosh, A. M. (2000). Marketing alcohol to young people: Implications for industry regulation and research policy. Addiction (Abingdon, England), 95(Suppl 4(July)), S597-S608. https://doi.org/10.1080/09652140020013809.

15. Jernigan, D. H. (2012). Global alcohol producers, science, and policy: The case of The International center for alcohol policies. American Journal of Public Health, 102(1), 80-89. https://doi.org/10.2105/AJPH.2011.300269.

16. Kypri, K., Voas, R. B., Langley, J. D., Stephenson, S. C. R., Begg, D. J., Tippetts, A. S., ... Davie, G. S. (2006). Minimum purchasing age for alcohol and traffic crash injuries among 15- to 19-year-olds in New Zealand. American Journal of Public Health, 96, 126-131.

17. Mathews, R., Thorn, M., \& Giorgi, C. (2013). Vested interests in addiction research and policy Is the alcohol industry delaying government action on alcohol health warning labels in Australia? 1889-1896. https://doi.org/10.1111/add.12338.

18. Moodie, R., Stuckler, D., Monteiro, C., Sheron, N., Neal, B., Thamarangsi, T., ... Casswell, S. (2013). Profits and pandemics: Prevention of harmful effects of tobacco, alcohol, and ultra-processed food and drink industries. The Lancet, 381(9867), 670-679. https://doi.org/10.1016/S0140-6736(12)62089-3.

19. Mosher, J. F. (2012). Joe camel in a bottle: Diageo, the Smirnoff brand, and the transformation of the youth alcohol market. American Journal of Public Health, 102(1), 5663. https://doi.org/10.2105/AJPH.2011.300387.

20. Munro, G., Wever, J., \& de (2009). Culture clash: Alcohol marketing and public health aspirations. Drug and Alcohol Review. https://doi.org/10.1080/09595230701827136 Retrieved from.

21. Nelson, J. P. (2010). Alcohol advertising bans, consumption and control policies in seventeen OECD countries, 1975-2000. Applied Economics, 42(7), 803-823. https://doi.org/10.1080/00036840701720952.

22. Noel, J. K., Babor, T. F., \& Robaina, K. (2017). Industry self-regulation of alcohol marketing: A systematic review of content and exposure research. Addiction, 112, 28-50. https://doi.org/10.1111/add.13410.

23. Paschall, M. J., Grube, J. W., \& Kypri, K. (2009). Alcohol control policies and alcohol consumption by youth: A multi-national study. Addiction, 104, 1849-1855.

24. QSR (2014). NVIVO 10. QSR International Pty Ltd.

25. Reynolds, R. I., Holder, H. D., \& Gruenewald, P. J. (1997). Community prevention and alcohol retail access. Addiction, 92, 261-272.

26. Rijksoverheid (2014). Drank en Horeca wet [Dutch licensing and catering act] 2014.

27. Roodbeen, R. T. J., \& Schelleman-Offermans, K. (2016). Alcohol- en tabaksverkoop aan jongeren 2016 [alcohol and tobacco sales to underage adolescents in 2016: National compliance rates]. Retrieved fromNijmegenwww.nuchter.nl/publicaties. 
Roodbeen, R.T.J., Schelleman-Offermans, K., Lemmens, P.H.H.M. Can vendors' age limit control measures increase compliance with the alcohol age limit? An evaluation of measures implemented by three Dutch liquor store chains. International Journal of Drug Policy: 2018, 61(11), 7-14

28. Roodbeen, R. T. J., Lie, K., \& Schelleman-Offermans, K. (2013). Alcoholverkoop aan jongeren 2013: ontwikkelingen in landelijke naleving van de leeftijdsgrenzen [alcohol sales to underage adolescents in 2013: National compliance rates in the Netherlands]. Nijmegen.

29. Roodbeen, R. T. J., Schelleman-Offermans, K., \& Lemmens, P. H. H. M. (2016). Alcohol and tobacco sales to underage buyers in Dutch supermarkets: Can the use of age verification systems increase seller's compliance? Journal of Adolescent Health, 58(6), 672-678. https://doi.org/10.1016/j.jadohealth.2016.03.005.

30. Roscoe, E. M., Fisher, W. W., Glover, A. C., \& Volkert, V. M. (2006). Evaluating the relative effects of feedback and contingent money for staff training of stimulus preference assessments. Journal of Applied Behavior Analysis, 39(1), 63-77. https://doi.org/10.1901/jaba.2006.7-05.

31. Rothengatter, T. (1991). Automatic policing and information systems for increasing traffic law compliance. Journal of Applied Behavior Analysis, 24(1), 85-87. https://doi.org/10.1901/jaba.1991.24-85.

32. Savell, E., Fooks, G., \& Gilmore, A. B. (2015). How does the alcohol industry attempt to influence marketing regulations? A systematic review. Addiction, 18-32. https://doi.org/10.1111/add.13048.

33. Scherer, M., Fell, J. C., Thomas, S., \& Voas, R. B. (2015). Effects of Dram shop, responsible beverage service training, and state alcohol control laws on underage drinking driver fatal crash ratios. Traffic Injury Prevention, 16(Suppl 2), S59-65. https://doi.org/10.1080/15389588.2015.1064909.

34. Shapiro, M., \& Kazemi, E. (2017). A review of training strategies to teach individuals implementation of behavioral interventions. Journal of Organizational Behavior Management, 37(1), 32-62. https://doi.org/10.1080/01608061.2016.1267066.

35. Sharma, L. L., Teret, S. P., \& Brownell, K. D. (2010). The food industry and self-regulation: Standards to promote success and to avoid public health failures. American Journal of Public Health, 100(2), 240-246. https://doi.org/10.2105/AJPH.2009.160960.

36. Smith, K. C., Cukier, S., \& Jernigan, D. H. (2014). Regulating alcohol advertising : content analysis of the adequacy of Federal and self-regulation of magazine advertisements, 2008-2010. American Journal of Public Health, 104(10), 2008-2010. https://doi.org/10.2105/AJPH.2013.301483.

37. Van Hoof, J. J., Gosselt, J. F., Baas, N., \& De Jong, M. D. (2012). Improving shop floor compliance with age restrictions for alcohol sales: Effectiveness of a feedback letter intervention. European Journal of Public Health, 22(5), 737-742 https://doi.org/ckr162 [pii]r10.1093/eurpub/ckr162.

38. Van Hoof, J. J., Gosselt, J. F., \& de Jong, M. D. T. (2010). Shop floor compliance with age restrictions for tobacco sales: Remote versus in-Store age verification. Journal of Adolescent Health, 46(2), 197-199. https://doi.org/10.1016/j.jadohealth.2009.06.009.

39. Van Hoof, J. J., Noordenburg, M. V.an, \& Jong, M. D.e (2008). Happy hours and other alcohol discounts in cafés: Prevalence and effects on Un derage adolescents. Journal of Public Health Policy, 29, 340-352. Retrieved from http://www.jstor.org/stable/40207195.

40. Van Hoof, J. J., Roodbeen, R. T. J., Krokké, J., Gosselt, J. F., \& Schelleman-Offermans, K. (2015). Alcohol sales to underage buyers in the Netherlands in 2011 and 2013. The Journal of Adolescent Health, 56(4), 468-470. https://doi.org/10.1016/j.jadohealth.2014.11.025.

41. VDN (Vereniging Drankenhandel Nederland). (n.d.). Retrieved October 7, 2018, from https://www.rndweb.nl/branches/vdn.

42. Wagenaar, A. C. (1993). Research effects public policy: The case of the legal drinking age in the United States. Addiction, 88, 75-81. 
Roodbeen, R.T.J., Schelleman-Offermans, K., Lemmens, P.H.H.M. Can vendors' age limit control measures increase compliance with the alcohol age limit? An evaluation of measures implemented by three Dutch liquor store chains. International Journal of Drug Policy: 2018, 61(11), 7-14

43. Wagenaar, A. C., \& Toomey, T. L. (2002). Effects of minimum drinking age laws: Review and analyses of the literature from 1960 to 2000 . Journal of Studies on Alcohol, S14,206225. https://doi.org/10.15288/jsas.2002.s14.206 April 2002.

\section{Tables and Figure}

Table 1. Descriptive data regarding participants in the survey.

\begin{tabular}{|l|l|l|l|}
\hline & Chain 1 & Chain 2 & Chain 3 \\
\hline $\begin{array}{l}\text { \% of participants working as affiliates of a chain (in a chain-owned liquor } \\
\text { store) }\end{array}$ & 15 & 100 & 68 \\
\hline - \% males & 83 & 90 & 88 \\
\hline - Average age (min-max) & $\begin{array}{l}48(28- \\
63)\end{array}$ & $\begin{array}{l}40(27- \\
62)\end{array}$ & $\begin{array}{l}46(20- \\
64)\end{array}$ \\
\hline - Average number of years affiliated with chain (min-max) & $13(1-36)$ & $15(1-40)$ & $16(<1-50)$ \\
\hline - \% of stores with >1 staff & 78 & 100 & 96 \\
\hline - Average number of staff members (min-max) & $2.0(1-6)$ & $5.3(2-8)$ & $3.9(1-25)$ \\
\hline
\end{tabular}

Note: To avoid identification of chains, the total number of stores and the total response per chain is not mentioned in this table.

Table 2. Interview results; key differences between the chains on domains.

\begin{tabular}{|c|c|c|c|}
\hline & $\begin{array}{l}\text { Chain } \\
1\end{array}$ & $\begin{array}{l}\text { Chain } \\
2\end{array}$ & $\begin{array}{l}\text { Chain } \\
3\end{array}$ \\
\hline \multicolumn{4}{|l|}{ Capturing processes in age verification } \\
\hline Obligated additional checks on IDs & - & + & - \\
\hline Fully implemented age verification system (AVS) & - & + & + \\
\hline \multicolumn{4}{|l|}{ Instructing staff } \\
\hline E-learning exam during application (with certificate) & - & + & - \\
\hline Employees receive a rulebook after application & - & - & + \\
\hline Magazine for employees, covering the age limit subject from various perspectives & - & - & + \\
\hline Reminders of mandatory age verification steps (a reading confirmation is required) & - & + & + \\
\hline \multicolumn{4}{|l|}{ Monitoring performance and feedback } \\
\hline Audits using minor and adolescent mystery shoppers testing age verification & - & + & + \\
\hline Audits using minor mystery shoppers testing the home delivery of alcohol & - & - & + \\
\hline In most cases, feedback is delivered directly after the audit & - & + & + \\
\hline Obligated additional checks by region/rayon manager & - & + & - \\
\hline \multicolumn{4}{|l|}{ Imposing consequences (affiliate liquor stores) } \\
\hline Neglecting processes could lead to a salary reduction & + & - & - \\
\hline Employees receive a personal letter from management & - & + & + \\
\hline Employees receive an official warning (this warning is included in their personnel file) & - & - & + \\
\hline All employees in the store receive a notification of the incidents & - & + & - \\
\hline An additional training is obligated & - & + & + \\
\hline $\begin{array}{l}\text { Employees will have a stern conversation with the region/rayon manager and a work } \\
\text { suspension }\end{array}$ & - & - & + \\
\hline Neglecting processes could lead to dismissal & - & + & + \\
\hline \multicolumn{4}{|l|}{ Imposing consequences (franchise liquor stores) } \\
\hline Consequences for the liquor store owner are included in the franchise agreement* & + & - & + \\
\hline
\end{tabular}


Roodbeen, R.T.J., Schelleman-Offermans, K., Lemmens, P.H.H.M. Can vendors' age limit control measures increase compliance with the alcohol age limit? An evaluation of measures implemented by three Dutch liquor store chains. International Journal of Drug Policy: 2018, 61(11), 7-14

* The specific content of consequences included in the agreement is unknown.

Table 3. Survey results; differences between the chains on domains.

\begin{tabular}{|c|c|c|c|c|c|c|}
\hline & \multirow{2}{*}{ Chain 1} & \multirow{2}{*}{$\begin{array}{l}\text { Chain } 2 \\
\%\end{array}$} & \multirow{2}{*}{ Chain 3} & \multicolumn{3}{|c|}{ Chi-square } \\
\hline & & & & $\mathrm{x} 2$ & & p-value \\
\hline \multicolumn{7}{|c|}{ Percentage of store owners in each chain applying different types of training for staff $(n=318)$} \\
\hline Individual oral training & 97 & 90 & 96 & 3.657 & 2 & .161 \\
\hline Group oral training & 15 & 28 & 51 & 21.158 & 2 & .000 \\
\hline Giving written information & 35 & 62 & 67 & 12.846 & 2 & .002 \\
\hline E-learning module & 0 & 100 & 29 & 94.245 & 2 & .000 \\
\hline Practical training AVSs & 3 & 21 & 25 & 8.443 & 2 & .015 \\
\hline \multicolumn{7}{|c|}{$\begin{array}{l}\text { Percentage of store owners in each chain indicating perceived risk of inspection by their head office } \\
(n=347)^{*}\end{array}$} \\
\hline Very low & 6 & 0 & 0 & & & \\
\hline Low & 13 & 0 & 0 & & & \\
\hline Not low/not high & 23 & 0 & 0 & & & \\
\hline High & 40 & 16 & 12 & & & \\
\hline Very high & 19 & 84 & 87 & & & \\
\hline \multicolumn{7}{|c|}{$\begin{array}{l}\text { Percentage of store owners in each chain indicating policies concerning consequences for store owners } \\
(n=345)\end{array}$} \\
\hline Personally addressed by head office manager & 49 & 89 & 86 & 37.247 & 2 & .000 \\
\hline Written warning from head office & 15 & 55 & 51 & 21.957 & 2 & .000 \\
\hline Obliged additional training & 2 & 13 & 39 & 31.447 & 2 & .000 \\
\hline Obliged to additionally train staff & 0 & 47 & 36 & 27.855 & 2 & .000 \\
\hline Mandatory interview with head office & 4 & 32 & 33 & 16.203 & 2 & .000 \\
\hline \multicolumn{7}{|c|}{ Percentage of store owners in each chain indicating policies concerning consequences for staff $(n=325)$} \\
\hline Personally addressed by liquor store owner/manager & 59 & 42 & 59 & 3.859 & 2 & .145 \\
\hline Written warning & 32 & 63 & 69 & 18.515 & 2 & .000 \\
\hline Obligated additional training & 5 & 24 & 68 & 70.145 & 2 & .000 \\
\hline Note in personnel file & 22 & 45 & 65 & 28.134 & 2 & .000 \\
\hline Obligated interview with head office manager & 5 & 45 & 61 & 41.428 & 2 & .000 \\
\hline Suspension & 5 & 18 & 43 & 25.228 & 2 & .000 \\
\hline Dismissal & 8 & 66 & 39 & 26.405 & 2 & .000 \\
\hline
\end{tabular}

Note: To avoid identification of the chains, only percentages are presented and the total number of participants per domain.

Due to social desirability bias, store owners were not asked about their own performance regarding processes in age verification.

$* \mathrm{X}^{2}=155.1 ; \mathrm{df}=8 ; \mathrm{p}=.000$. 
Roodbeen, R.T.J., Schelleman-Offermans, K., Lemmens, P.H.H.M. Can vendors' age limit control measures increase compliance with the alcohol age limit? An evaluation of measures implemented by three Dutch liquor store chains. International Journal of Drug Policy: 2018, 61(11), 7-14

Table 4. Requesting IDa rates, AVSb usage, compliance after usage/ID requests and total compliance per chain for the complete and linked datasets.

\begin{tabular}{|c|c|c|c|c|c|c|c|}
\hline & $\begin{array}{l}\text { Requesting } \\
\text { ID }\end{array}$ & $\begin{array}{l}\text { AVS used } \\
\text { after } \\
\text { requesting } \\
\text { ID }\end{array}$ & $\begin{array}{l}\text { Compliance } \\
\text { after using } \\
\text { AVS }\end{array}$ & $\begin{array}{l}\text { AVS not used } \\
\text { after } \\
\text { requesting ID }\end{array}$ & $\begin{array}{l}\text { Compliance } \\
\text { after not } \\
\text { using AVS }\end{array}$ & \begin{tabular}{|l} 
Total \\
compliance \\
after \\
requesting ID
\end{tabular} & $\begin{array}{l}\text { Total } \\
\text { compliance }\end{array}$ \\
\hline \multicolumn{8}{|l|}{\begin{tabular}{|l}
$\%$ \\
complete \\
dataset \\
\end{tabular}} \\
\hline Chain 1 & $54 c$ & 18 & 75 & 82 & 63 & 65 & $35 d$ \\
\hline Chain 2 & $95 c$ & 27 & 100 & 73 & 78 & 84 & $80 d$ \\
\hline Chain 3 & $95 c$ & 26 & 93 & 74 & 82 & 85 & $80 d$ \\
\hline $\begin{array}{l}\text { Total } \\
(\mathrm{n}=387)\end{array}$ & 317 (82\%)e & 77 (24\%) & 70 (91\%) & $240(76 \%)$ & $185(77 \%)$ & $255(80 \%)$ & 255 (66\%)f \\
\hline \multicolumn{8}{|c|}{$\%$ linked dataset } \\
\hline Chain 1 & $50 c$ & 24 & 75 & 77 & 54 & 59 & $29 d$ \\
\hline Chain 2 & $95 c$ & 26 & 100 & 74 & 81 & 86 & 81d \\
\hline Chain 3 & $98 c$ & 29 & 90 & 71 & 83 & 85 & $83 d$ \\
\hline $\begin{array}{l}\text { Total } \\
(\mathrm{n}=179)\end{array}$ & 158 (88\%)e & $44(28 \%)$ & 40 (91\%) & $114(72 \%)$ & 90 (79\%) & $130(82 \%)$ & 130 (73\%)f \\
\hline
\end{tabular}

Note: To avoid identification of the chains, only percentages and total results are presented.

${ }^{\mathrm{a}} \mathrm{ID}=$ Identification Document.

${ }^{\mathrm{b}}$ AVS $=$ Age Verification System.

$c, d, e, f$ Testing the differences between:

requesting ID rates between chains $\left(X^{2}\right.$ complete $=97.1, d f=2, p=.000 ; X^{2}$ linked $\left.=59.7, d f=2, p=.000\right)$;

total compliance between chains $\left(X^{2}\right.$ complete $=76.8, d f=2, p=.000 ; X^{2}$ linked $\left.=39.5, d f=2, p=.000\right)$;

total requesting ID rates between the complete and linked dataset $\left(X^{2}=3.7, d f=2, p=.056\right)$;

total compliance between the complete and linked dataset $\left(X^{2}=2.6, d f=2, p=.110\right)$, respectively.

Table 5. Linked data; survey results (liquor store owners in each chain indicating perceived risk of inspection) and mystery shopping data.

\begin{tabular}{|c|c|c|c|c|c|c|c|c|c|c|c|}
\hline & \multicolumn{3}{|c|}{$\begin{array}{l}\% \text { survey results } \\
(n=166) a\end{array}$} & \multicolumn{8}{|c|}{$\%$ mystery shopping data $(n=166) b$} \\
\hline & \multirow[b]{2}{*}{ Chain 1} & \multirow[b]{2}{*}{ Chain 2} & \multirow[b]{2}{*}{ Chain 3} & \multicolumn{2}{|c|}{ Chain 1} & \multicolumn{2}{|c|}{ Chain 2} & \multicolumn{2}{|l|}{ Chain 3} & \multicolumn{2}{|l|}{ Total } \\
\hline & & & & $\begin{array}{l}\text { ID req. } \\
\text { rates }\end{array}$ & Compl. & $\begin{array}{l}\text { ID req. } \\
\text { rates }\end{array}$ & Compl. & $\begin{array}{l}\text { ID req. } \\
\text { rates }\end{array}$ & Compl. & $\begin{array}{l}\text { ID req. } \\
\text { rates }\end{array}$ & Compl. \\
\hline Very low & 3 & 0 & 1 & 0 & 0 & 0 & 0 & 100 & 100 & 50 & 50 \\
\hline Low & 16 & 0 & 0 & 20 & 20 & 0 & 0 & 0 & 0 & 20 & 20 \\
\hline $\begin{array}{l}\text { Not low/not } \\
\text { high }\end{array}$ & 19 & 0 & 1 & 33 & 17 & 0 & 0 & 100 & 100 & 43 & 29 \\
\hline High & 39 & 17 & 12 & 58 & 33 & 100 & 100 & 92 & 67 & 80 & 60 \\
\hline Very highc & 23 & 83 & 86 & 71 & 43 & 93 & 77 & 99 & 86 & 96 & 81 \\
\hline
\end{tabular}

Note: To avoid identification of the chains, only percentages are presented and the total number of participants per dataset.

${ }^{a} X^{2}=66.8 ; d f=8 ; p=.000 .{ }^{b}$ due to a limited cell-count, Chi-square analyses between the chains were only feasible in the 'very high' category.

${ }^{c} X^{2}$ ID req. rates $=13.0 ; d f=2 ; p=.001 . X^{2}$ Compl. $=8.3 ; d f=2 ; p=.015$. 